\title{
USGS MODIS Direct Broadcast - Reception and Processing at the USGS Center for Earth Resources Observation and Science
}

The Moderate Resolution Imaging Spectroradiometer (MODIS) is a key instrument aboard NASA's Terra Earth Observing System (EOS) AM and Aqua EOS PM spacecrafts.

These instruments use a near-circular, sun-synchronous orbit. Terra's orbit passes from north to from south across the equator in the morning (10:30 a.m.), while Aqua passes south to north over the equator in the afternoon (1:30 p.m.). The viewing swath width is 2,330 km, which means MODIS views the entire surface of the Earth every 1 to 2 days. Its detectors measure 36 spectral bands and acquire data at three spatial resolutions:

250-m resolution. Bands 1-2

500-m resolution. Bands 3-7

1000-m resolution. Bands 8-36

One of the unique features of the MODIS instrument is its capability to broadcast raw data to appropriately equipped ground stations. In April 2002, the U.S. Geological Survey (USGS) Center for Earth Resources Observation and Science (EROS) in Sioux Falls, South Dakota, became a direct broadcast (DB) ground station for data over the conterminous United States.

Since then, EROS processes and distributes seven levels of MODIS DB products. These products are as follows:

1. Level 1B (L1B) calibrated radiance

2. Level $2 \mathrm{R}(\mathrm{L} 2 \mathrm{R})$ surface reflectance

3. Level $2 \mathrm{G}$ (L2G) calibrated radiance gridded to uniform time/space intervals

4. Level 2RG (L2RG) surface reflectance gridded to uniform time/space intervals

5. Level 3V (L3V) vegetation indices. Normalized Difference Vegetation Index (NDVI) and Enhanced Vegetation Index (EVI) bands

6. Level 3VG (L3VG) vegetation indices gridded to uniform time/space intervals

7. Seven-day composites built from the daily surface reflectance products of the conterminous United States, with state-based composites also available.
MODIS DB data play a vital role in the development of validated, global, interactive Earth system models that are able to predict global change accurately enough to assist policy makers in making sound decisions concerning the protection of our environment.

MODIS DB data are used to support state and local governments, Federal Emergency Management Agency, emergency services, relief agencies, as well as government disaster management teams. Other uses of the data include land characterization research, generation of land-related products, input to global and regional climate models, and surface energy balance models. Applications for the vegetation indices include agricultural monitoring and forecasting, land-use planning, land cover characterization, and land cover change detection.

The most recent five days of MODIS DB data are available for review and download at no cost from the following EROS sites:

\section{- MODIS DB Web site http://modisdb.usgs.gov/}

- MODIS DB retrieval site http://edc.usgs.gov/modisdata/

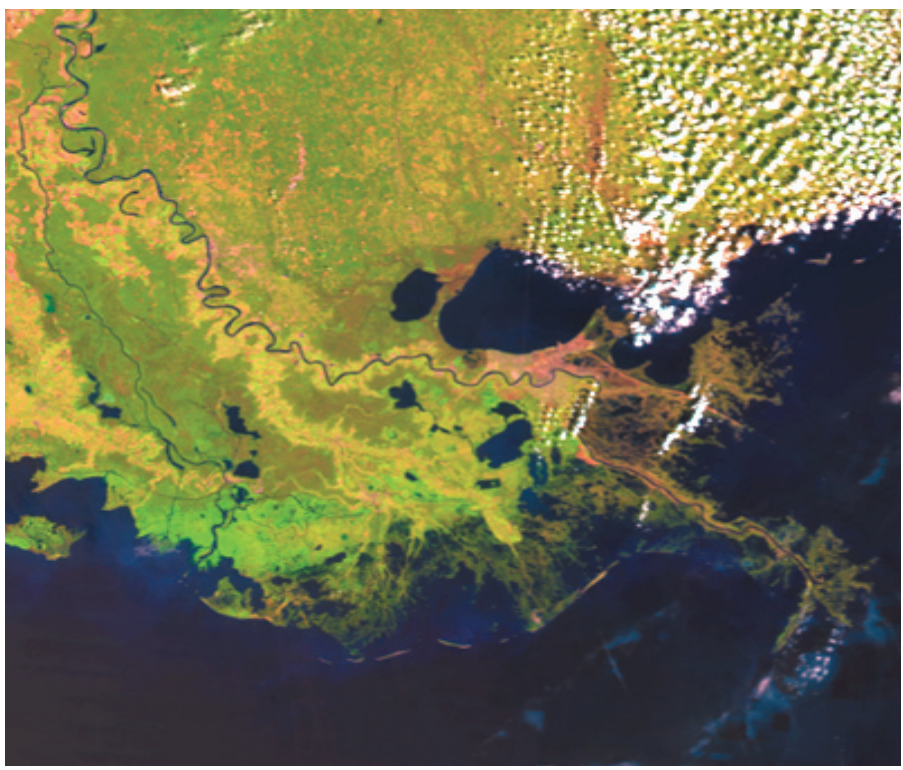

The MODIS DB Terra image above, was acquired on September 20, 2005. It shows New Orleans, Louisiana, 22 days after Hurricane Katrina made landfall, causing intense flooding in the city.

\section{Contact information: modisdb@usgs.gov}

